\title{
Torque Performance Enhancement of Flux- Switching Permanent Magnet Machines with Dual Sets of Magnet Arrangements
}

\author{
Canruo Chen, Xiang Ren, Dawei Li, Member, IEEE, Ronghai Qu, Fellow, IEEE, Kang Liu, and \\ Tianjie Zou, Member, IEEE
}

\begin{abstract}
Torque performance, especially torque density, is a critical performance index for flux-switching permanent magnet (FSPM) machine which is attractive for propulsion system. In this paper, a novel FSPM machine with dual sets of magnet arrangements is proposed. With the novel topology, torque density of the proposed machine is significantly improved due to much increased working harmonic contents of magnetomotive force (MMF). Moreover, the cogging torque is also inherently reduced, which makes the proposed machine a promising candidate in FSPM machine family. The operating principle of the proposed FSPM machine is revealed based on the MMF-permeance model and numerical finite element analysis (FEA). The effect of geometric parameters such as magnet thickness, auxiliary tooth width and rotor tooth width on the average torque and cogging torque is also investigated. Finally, a prototype has been manufactured to validate the analysis conclusion. With experimental test results, it is demonstrated that the proposed topology can achieve $\mathbf{3 0 . 8 \%}$ higher torque density, $\mathbf{7 9 . 4 \%}$ lower cogging torque and $15.6 \%$ higher power factor than the conventional counterpart.
\end{abstract}

Index Terms - Cogging torque, finite element analysis (FEA), flux-switching permanent magnet (FSPM) machine, magnet arrangement, torque density.

\section{INTRODUCTION}

$I^{\mathrm{r}}$ $\mathrm{N}$ recent decades, permanent magnet (PM) machines have been widely used in various industry applications, such as ship propulsion, aerospace equipment and electric vehicle. Flux-switching permanent magnet (FSPM) machine did not draw much attention when first proposed in [1] due to its relatively poor electromagnetic performance and immature design methods. With the extension of electric machine theory and development of high performance magnetic materials, FSPM machine has received much increased attention due to its simple rotor structure and fault-tolerance capability [2]-[8]. Besides, the stator PM topology benefits the thermal management. FSPM machines have become attractive

Manuscript received December 4, 2020; revised February 8, 2021; accepted February 18,2021 . This work was jointly supported in part by National Natural Science Foundations of China under Grant 51761135120, in part by National Natural Science Foundations of China under Grant 51807076. (Corresponding author: Xiang Ren)

Canruo Chen, Xiang Ren, Dawei Li, Ronghai Qu and Kang Liu, are with the School of Electrical and Electronic Engineering, Huazhong University of candidates for low-speed high-torque applications [9] [10], while their key performance index still needs to be further improved in terms of torque density and cogging torque level [11] [12] which has become research hotspots in recent years.

To improve torque density, many experts have developed and investigated various high-performance FSPM machines. J. T. Chen et al. [13] proposed a novel E-core FSPM machine which could exhibit $15 \%$ higher torque capability than conventional 12/10 stator/rotor pole machine. Moreover, the C-core FSPM topology [14] was proposed and it was demonstrated that $40 \%$ higher torque density could be realized compared with the conventional 12/10 stator/rotor pole FSPM machine. L. Shao et al. [15] investigated a novel FSPM machine with overlapping windings and the machine could provide $17.6 \%$ higher torque density than conventional $12 / 10$ stator/rotor pole nonoverlapping winding machine. To increase utilization of armature slot, W. Hua et al. [16] proposed an outer-rotor FSPM machine with wedge-shaped magnets which could produce $40 \%$ higher torque than rectangular-shaped magnets-based machine. Besides, consequent-pole FSPM machines with flux bridges in stator core [17] and sandwiched FSPM machines using Vshaped magnets [18] were introduced to increase the PM utilization ratio. The multi-tooth FSPM machines were investigated for the first time in [19] and the optimal slot/pole combinations were discussed to exhibit high torque capabilities in [20]. It is shown that the multi-tooth FSPM machine can exhibit higher torque density than conventional 12/10 stator/rotor pole machine. The multi-tooth topology provides the feasibility of dual sets of magnet arrangements to further increase the torque density.

In this paper, a novel topology of FSPM machine with dual sets of magnet arrangements is introduced. With the novel topology, torque density of the proposed machine is significantly improved due to much increased working harmonic contents of MMF. The operating principle of the proposed FSPM machine is revealed based on MMFpermeance model and numerical FEA in Section II. In Section III, the electromagnetic performance is compared with the conventional counterpart and it is demonstrated that the

Science and Technology, Wuhan 430074, China (e-mail: canruo1206@163.com; renxiang_2013@126.com; daweili@hust.edu.cn; ronghaiqu@hust.edu.cn; kang_liu_ami@163.com;).

Tianjie Zou is with the Power Electronics, Machines and Control (PEMC) Group, University of Nottingham, NG7 2RD, Nottingham, U. K. (e-mail: Tianjie.Zou@nottingham.ac.uk). 


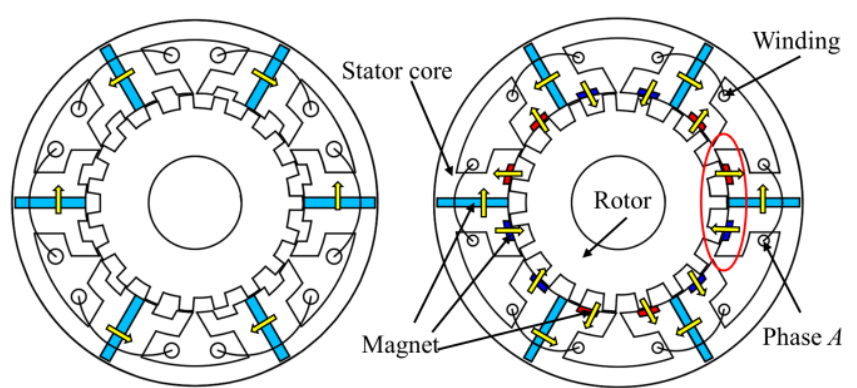

(a)

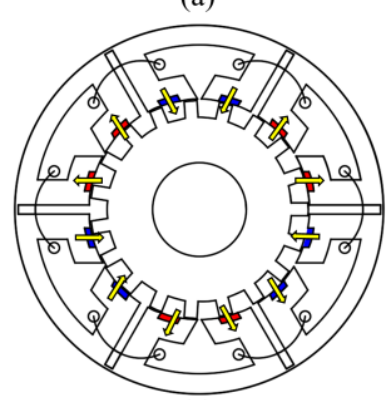

(c) (b)

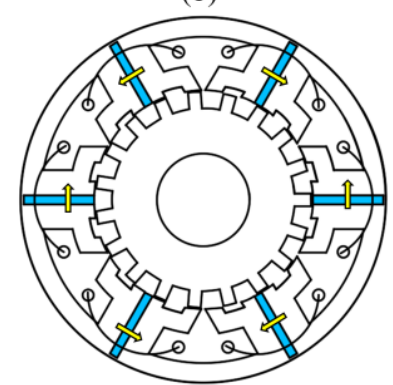

(d)
Fig. 1. Basic topologies. (a) Conventional multi-tooth FSPM machine. (b) Proposed FSPM machine. (c) Machine I. (d) Machine II.

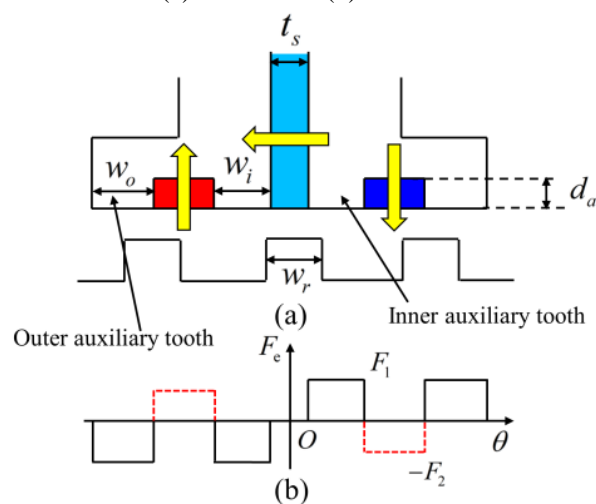

(b)

Fig. 2. MMF-permeance model. (a) Sketch part in the red circle in Fig. 1(b). (b) Simplified equivalent MMF function.

proposed topology can achieve $30.8 \%$ higher torque density, $79.4 \%$ lower cogging torque and $15.6 \%$ higher power factor. Then, Section IV will be devoted to the analysis of influence of geometric parameters on torque performance. Furthermore, a prototype has been manufactured to verify the analysis results in Section V. Finally, some conclusions will be drawn in Section VI.

\section{Machine Topology And Operating PRINCIPLE}

In this section, operating principle of the proposed FSPM machine with dual sets of magnet arrangements is analyzed and some expressions are derived to investigate the contributions of the working harmonics. For simplicity, some assumptions are made as follows.

1) The symmetrical three-phase sinusoidal current sources are applied to drive the FSPM machines.

2) The axis of the phase $A$, the initial position of the rotor tooth axis and the origin of the coordinates are in alignment.

\section{A. Machine Topology}

To obtain high torque density, stator auxiliary tooth-slot structure is adopted to improve modulation effect [19] [21]. The conventional multi-tooth and proposed FSPM machines are depicted in Fig. 1(a) and Fig. 1(b) respectively. Different from the conventional counterpart, there are dual sets of magnet arrangements in the proposed topology, in which the yellow arrows represent the magnetization direction of the magnets. Besides, the proposed machine can be seen as the combination of machine I and machine II, as shown in Fig. 1(c) and Fig. 1(d) respectively. The sketch part in the red circle in Fig. 1(b) and the simplified equivalent MMF function neglecting the magnetic reluctance of the iron core are shown in Fig. 2, where $t_{s}$ is the spoke-type magnet thickness, $w_{o}$ is the outer auxiliary tooth width, $w_{i}$ is the inner auxiliary tooth width, $d_{a}$ is the auxiliary slot depth, and $w_{r}$ is the rotor tooth width. Due to the magnets in the auxiliary stator slots, there are differences between the simplified equivalent MMF functions of conventional multi-tooth and proposed FSPM machines. The different parts are marked as red line. $F_{1}$ and $F_{2}$ are the amplitudes of MMF drop in the airgap under the auxiliary teeth and slots respectively.

\section{B. Operating Principle}

The no-load air-gap flux density in FSPM machines can be given as [22]

$$
\begin{aligned}
B(\theta, t) & =\frac{g}{\mu_{0}} F_{m}(\theta) \Lambda_{s}(\theta) \Lambda_{r}(\theta, t) \\
& =F_{\mathrm{e}}(\theta) \Lambda_{r}(\theta, t)
\end{aligned}
$$

where $\theta$ is the angle along the circumference in the airgap, $g$ is the airgap length, $\mu_{0}$ is the permeability of air, $F_{m}(\theta)$ is the PM $\mathrm{MMF}, \Lambda_{s}(\theta)$ is the stator permeance with slotted stator and smoothed rotor, and $\Lambda_{r}(\theta, t)$ is the rotor permeance with slotted rotor and smoothed stator, and $F_{\mathrm{e}}(\theta)$ is the equivalent MMF after being modulated by the stator auxiliary teeth.

The MMF, which refers to the equivalent MMF in this paper, can be expressed as

$$
F_{\mathrm{e}}(\theta)=\sum_{n=1,3,5 \ldots} F_{\mathrm{e} n} \sin \left(n \frac{N_{s}}{2} \theta\right)
$$

where $F_{\mathrm{e} n}$ is the amplitude of the $n^{\text {th }}$ order harmonic, $N_{s}$ is the number of stator slots.

The rotor permeance function can be written as

$$
\Lambda_{r}(\theta, t)=\Lambda_{0}+\sum_{m=1,2,3 \ldots} \Lambda_{m} \cos \left(m N_{r} \theta-m \omega t\right)
$$

where $\omega$ is the electrical angular velocity, $N_{r}$ is the number of the rotor slots, $\Lambda_{0}$ is the constant permeance, and $\Lambda_{m}$ is the amplitude of the $m^{\text {th }}$ order harmonic.

Thus, the no-load air-gap flux density can be obtained as

$$
\begin{aligned}
B(\theta, t) & =\sum_{n=1,3,5 \ldots} F_{\mathrm{e} n} \Lambda_{0} \sin \left(n \frac{N_{s}}{2} \theta\right) \\
& +\sum_{n=1,3,5 \ldots} \sum_{m=1,2,3 \ldots} \frac{F_{\mathrm{e} n} \Lambda_{m}}{2} \sin \left[\left(n \frac{N_{s}}{2} \pm m N_{r}\right) \theta \mp m \omega t\right] .
\end{aligned}
$$

Considering the flux linkages interacting with phase $A$, the back EMF of phase $A$ can be given as

$$
e_{A}(t)=-\frac{d}{d t}\left[\int_{0}^{2 \pi} r_{g} l_{s} B(\theta, t) N(\theta) d \theta\right]
$$

where $r_{g}$ is the radius of the stator bore, $l_{s}$ is the stack length. The winding function $N(\theta)$ can be expressed as [23] 


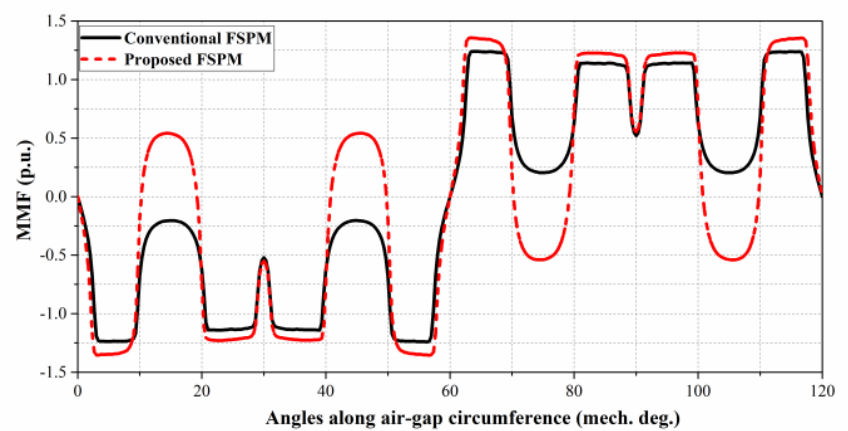

Fig. 3. Comparison of FEA-predicted MMF distributions of the conventional multi-tooth and proposed FSPM machines.

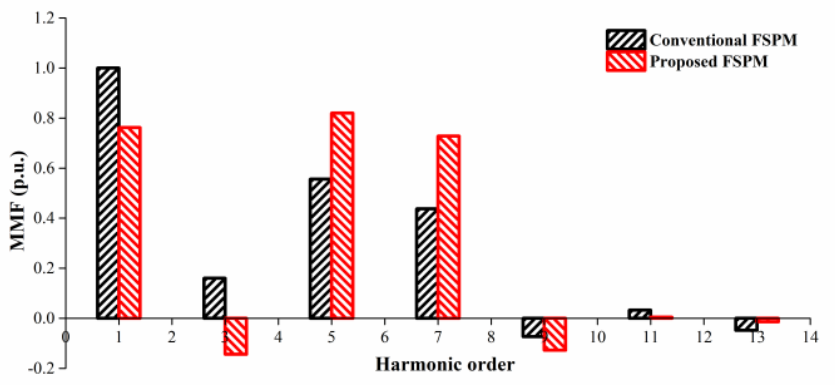

Fig. 4. FFT analysis results of MMF distributions of the conventional multitooth and proposed FSPM machines.

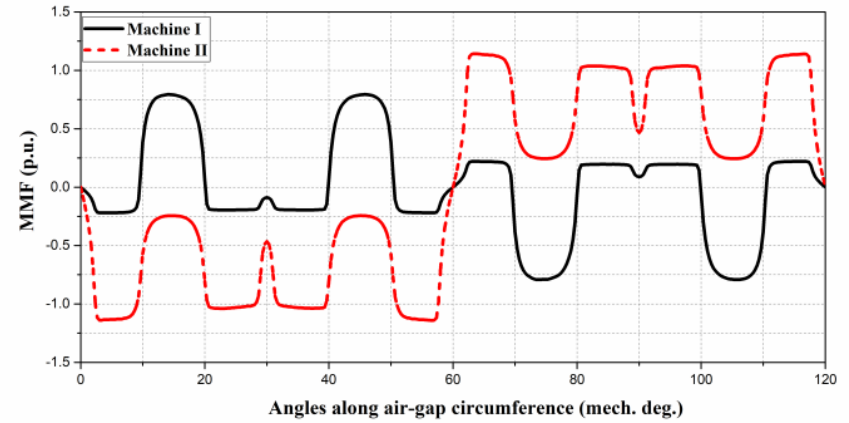

Fig. 5. Comparison of FEA-predicted MMF distributions of machine I and II.

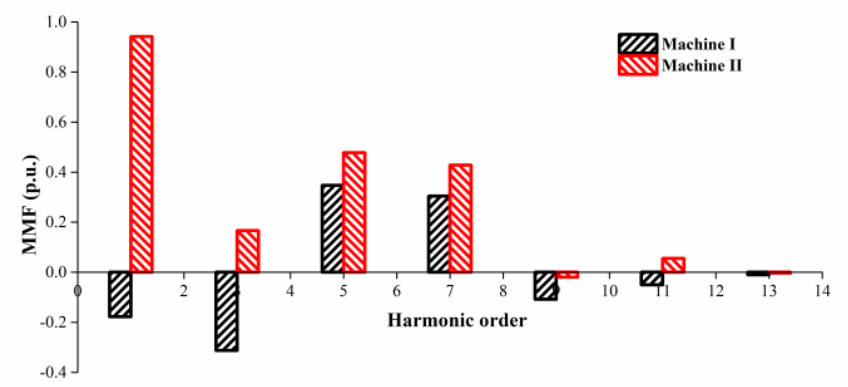

Fig. 6. FFT analysis results of MMF distributions of machine I and II.

$$
N(\theta)=\sum_{j=2,4,8,10 \ldots .} \frac{2 N_{c}}{j \pi} k_{w j} \cos (j \theta)
$$

where $N_{c}$ is number of series turns per phase, $k_{w j}$ is the winding factor of $j$-pole-pair flux density harmonic.

From expression (5), the pole pair number of the no-load airgap flux density and armature field should be equal to produce back EMF. Thus, the following equation should be satisfied

$$
j=\left|n \frac{N_{s}}{2} \pm m N_{r}\right| \text {. }
$$

In the concentrated-winding machine with six stator slots, the winding factors of the odd-pole-pair flux density harmonics are zero. Therefore, only the even-pole-pair flux density harmonics need to be considered when calculating the back EMF. The constant term of rotor permeance function can be ignored when analyzing the back EMF, since only the rotating magnetic field can produce the back EMF. Based on the above analysis, the variable $m$ can only be odd.

For symmetrical three-phase FSPM machines, the right side of (7) is a multiple of 3 when $m$ is 3 . But the flux density harmonics, whose pole pair numbers are multiples of 3 , are nonworking harmonics because of the zero winding factor. When $m$ is larger than or equal to 5 , the corresponding amplitude of the permeance function is small enough to be neglected. Thus, only the fundamental permeance harmonic, i.e. $m=1$, is taken into account when calculating the back EMF and electromagnetic torque.

Only considering main working flux density harmonics which contribute to back EMF, the expression (4) can be modified as

$$
\begin{aligned}
B(\theta, t)= & B_{2} \sin \left[\left(\frac{7 N_{s}}{2}-N_{r}\right) \theta+\omega t\right]+B_{4} \sin \left[\left(N_{r}-\frac{5 N_{s}}{2}\right) \theta-\omega t\right] \\
& +B_{8} \sin \left[\left(\frac{9 N_{s}}{2}-N_{r}\right) \theta+\omega t\right]+B_{10} \sin \left[\left(N_{r}-\frac{3 N_{s}}{2}\right) \theta-\omega t\right] \\
& +B_{14} \sin \left[\left(\frac{11 N_{s}}{2}-N_{r}\right) \theta+\omega t\right]+B_{16} \sin \left[\left(N_{r}-\frac{N_{s}}{2}\right) \theta-\omega t\right] \\
& +B_{20} \sin \left[\left(\frac{13 N_{s}}{2}-N_{r}\right) \theta+\omega t\right]+B_{22} \sin \left[\left(\frac{N_{s}}{2}+N_{r}\right) \theta-\omega t\right] .
\end{aligned}
$$

Then, the back EMF of phase $A$ can be expressed as

$$
e_{A}(t)=2 r_{g} l_{s} N_{c} \omega \cos (\omega t) \times
$$

$$
\left[\begin{array}{c}
-\frac{B_{2} k_{7 N_{s}}-N_{r}}{\frac{7 N_{s}}{2}-N_{r}}+\frac{B_{4} k_{N_{r}-\frac{5 N_{s}}{2}}}{N_{r}-\frac{5 N_{s}}{2}}-\frac{B_{8} k_{9 N_{s}}-N_{r}}{\frac{9 N_{s}}{2}-N_{r}}+\frac{B_{10} k_{N_{r}-\frac{3 N_{s}}{2}}}{N_{r}-\frac{3 N_{s}}{2}} \\
-\frac{B_{14} k_{11 N_{s}}-N_{r}}{\frac{11 N_{s}}{2}-N_{r}}+\frac{B_{16} k_{N_{r}-\frac{N_{s}}{2}}}{N_{r}-\frac{N_{s}}{2}}-\frac{B_{20} k_{13 N_{s}}-N_{r}}{\frac{13 N_{s}}{2}-N_{r}}+\frac{B_{22} k_{N_{s}}+N_{r}}{\frac{N_{s}}{2}+N_{r}}
\end{array}\right]
$$

The characteristics of main working harmonic are illustrated in Table I. The electromagnetic torque with $i_{d}=0$ can be given as

$$
\begin{aligned}
& T=\frac{3 E_{A} I_{A}}{\omega / N_{r}} \\
& =3 \sqrt{2} r_{g} l_{s} N_{c} N_{r} I_{A} \times \\
& {\left[\begin{array}{c}
-\frac{B_{2} k_{\frac{7 N_{s}}{2}-N_{r}}}{\frac{7 N_{s}}{2}-N_{r}}+\frac{B_{4} k_{N_{r}-\frac{5 N_{s}}{2}}}{N_{r}-\frac{5 N_{s}}{2}}-\frac{B_{8} k_{\frac{9 N_{s}}{2}-N_{r}}}{\frac{9 N_{s}}{2}-N_{r}}+\frac{B_{10} k_{N_{r}-\frac{3 N_{s}}{2}}}{N_{r}-\frac{3 N_{s}}{2}} \\
-\frac{B_{14} k_{11 N_{s}}-N_{r}}{\frac{11 N_{s}}{2}-N_{r}}+\frac{B_{16} k_{N_{r}-\frac{N_{s}}{2}}}{N_{r}-\frac{N_{s}}{2}}-\frac{B_{20} k_{13 N_{s}}-N_{r}}{\frac{13 N_{s}}{2}-N_{r}}+\frac{B_{22} k_{\frac{N_{s}}{2}+N_{r}}}{\frac{N_{s}}{2}+N_{r}}
\end{array}\right]}
\end{aligned}
$$

where $E_{A}$ is the root-mean-square (RMS) value of the phase back EMF, $I_{A}$ is the RMS value of the phase current. 


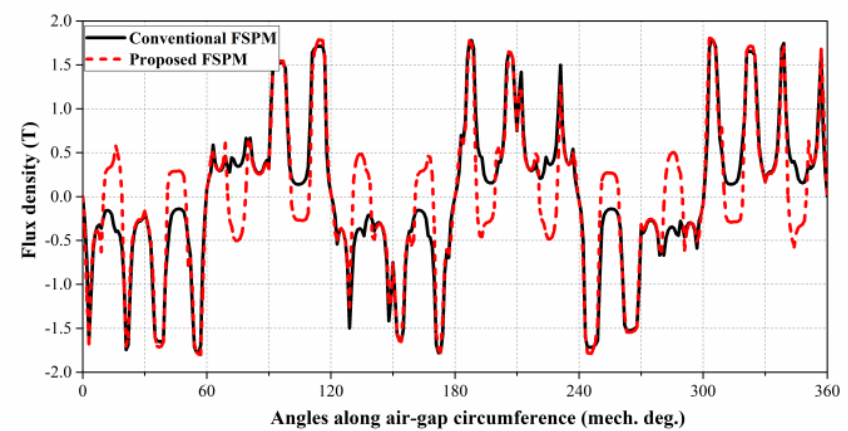

Fig. 7. FEA-predicted no-load air-gap flux density distributions at $t=0$.

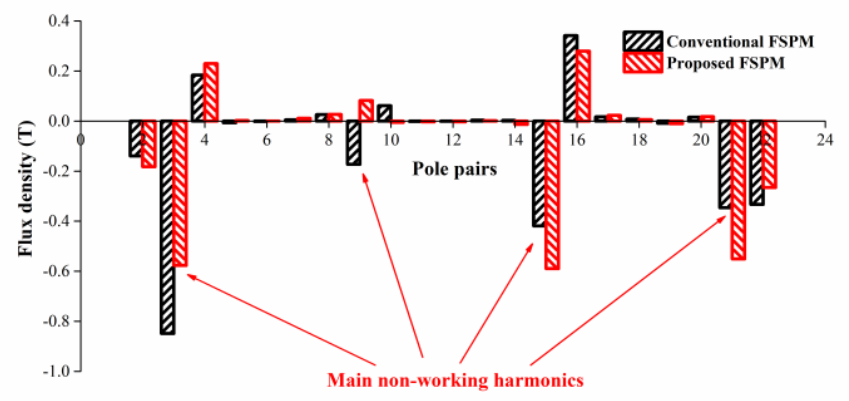

Fig. 8. FFT analysis results of no-load air-gap flux density distributions at $t=0$.

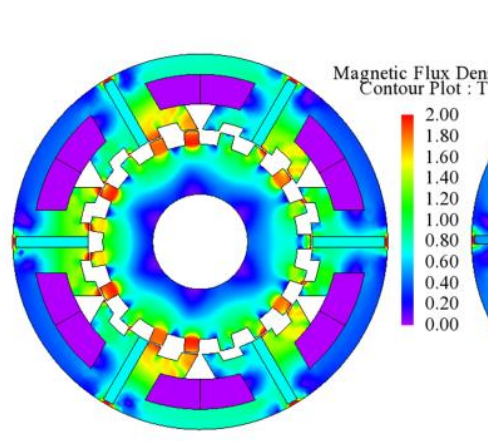

(a)

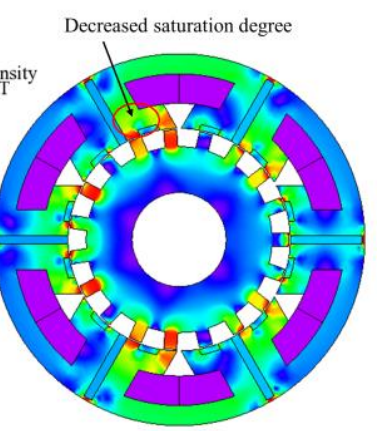

(b)
Fig. 9. No-load contour plots. (a) Conventional multi-tooth FSPM machine. (b) Proposed FSPM machine.

Fig. 3 shows the comparison of FEA-predicted MMF distributions of conventional multi-tooth and proposed FSPM machines. This figure is shown based on per unit system and the amplitude of $1^{\text {st }}$ order MMF harmonic of conventional one is set as the base value.

Fig. 4 shows FFT analysis results of MMF distributions of conventional multi-tooth and proposed machines. It is noted that $1^{\text {st }}$ order MMF harmonic reduces significantly, while $5^{\text {th }}$ and $7^{\text {th }}$ order harmonics show a marked increase compared with the conventional one. To research the nature of proposed topology, the comparison of FEA-predicted MMF distributions of machine I and II is shown in Fig. 5. Considering that the permeability of iron core is nonlinear, the frozen permeability method [24] has been taken to obtain the accurate results.

Fig. 6 shows the FFT analysis results of MMF distributions of machine I and II. The $1^{\text {st }}$ order MMF harmonic of machine I is negative while $5^{\text {th }}$ and $7^{\text {th }}$ order MMF harmonics are all positive. Thus, the reduction of $1^{\text {st }}$ order MMF harmonic is due to the negative contribution of machine I and decreased positive contribution of machine II. Besides, the different signs of $3^{\text {rd }}$ and $11^{\text {th }}$ order MMF harmonics contribute to the decrease of the
TABLE I

CHARACTERISTICS OF MAIN WORKING HARMONICS

\begin{tabular}{ccc}
\hline \hline Pole pairs & Amplitude & Speed \\
\hline$\frac{7 N_{s}}{2}-N_{r}, 2$ & $B_{2}=\frac{F_{\mathrm{e} 7} \Lambda_{1}}{2}$ & $-\frac{\omega}{7 N_{s} / 2-N_{r}}$ \\
$N_{r}-\frac{5 N_{s}}{2}, 4$ & $B_{4}=-\frac{F_{\mathrm{e} 5} \Lambda_{1}}{2}$ & $\frac{\omega}{5 N_{s} / 2-N_{r}}$ \\
$\frac{9 N_{s}}{2}-N_{r}, 8$ & $B_{8}=\frac{F_{\mathrm{e} 9} \Lambda_{1}}{2}$ & $-\frac{\omega}{9 N_{s} / 2-N_{r}}$ \\
$N_{r}-\frac{3 N_{s}}{2}, 10$ & $B_{10}=-\frac{F_{\mathrm{e} 3} \Lambda_{1}}{2}$ & $\frac{\omega}{3 N_{s} / 2-N_{r}}$ \\
$\frac{11 N_{s}}{2}-N_{r}, 14$ & $B_{14}=\frac{F_{\mathrm{e} 11} \Lambda_{1}}{2}$ & $-\frac{\omega}{11 N_{s} / 2-N_{r}}$ \\
$N_{r}-\frac{N_{s}}{2}, 16$ & $B_{16}=-\frac{F_{\mathrm{e} 1} \Lambda_{1}}{2}$ & $\frac{\omega}{N_{s} / 2-N_{r}}$ \\
$\frac{13 N_{s}}{2}-N_{r}, 20$ & $B_{20}=\frac{F_{\mathrm{e} 13} \Lambda_{1}}{2}$ & $-\frac{\omega}{13 N_{s} / 2-N_{r}}$ \\
$\frac{N_{s}}{2}+N_{r}, 22$ & $B_{22}=\frac{F_{\mathrm{e} 1} \Lambda_{1}}{2}$ & $\frac{\omega}{N_{s} / 2-N_{r}}$ \\
\hline \hline
\end{tabular}

corresponding MMF harmonics.

The no-load air-gap flux density distributions at $t=0$ are shown in Fig. 7, and the corresponding FFT analysis results are given in Fig. 8. It should be noted that 3/9/15/21-pole-pair flux density harmonic originates from corresponding $1^{\text {st }} / 3^{\text {rd }} / 5^{\text {th }} / 7^{\text {th }}$ order MMF harmonic which is modulated by the constant term of rotor permeance.

It is shown that the 3-pole-pair flux density harmonic accounts for a large proportion and does not make contributions to back EMF due to the zero rotating speed. The amplitude of the 3-pole-pair flux density harmonic decreases by $32.1 \%$, and 16/22-pole-pair flux density harmonic decreases at the same time. As shown in Table I, the 2-pole-pair and 4-pole-pair flux density harmonics are modulated from $7^{\text {th }}$ and $5^{\text {th }}$ order MMF harmonics respectively. It is noted that the 3-pole-pair flux density harmonic is modulated from $1^{\text {st }}$ order MMF harmonic, i.e. the fundamental MMF harmonic. It can be seen from Fig. 2(b) that the red lines can weaken the fundamental MMF harmonic represented by the black lines. And the enhancement of 2-pole-pair and 4-pole-pair flux density harmonics indicates the increase of $7^{\text {th }}$ and $5^{\text {th }}$ order MMF harmonics. Thus, 3-polepair flux density harmonic is reduced while the 15-pole-pair and 21-pole-pair flux density harmonics increase. Then, decreased saturation degree can be realized by the reduction of 3-pole-pair flux density harmonic in proposed FSPM machines, as shown in Fig. 9.

In conventional multi-tooth FSPM machines, non-working harmonics account for a large proportion and cannot make contributions to the back EMF and torque. Due to the saturation limitation, the main working harmonics cannot be improved by further increasing the magnet usage. As a comparison, the novel FSPM machine with dual sets of magnet arrangements is proposed.

In order to validate the foregoing analysis, the back EMF and torque contributions of main working harmonics are shown in Table II. It can be observed that the 2-pole-pair and 4-pole-pair flux density harmonics exhibits dominant back EMF and torque contributions. The total calculated and FEA-predicted back 
TABLE II

BACK EMF AND TORQUE CONTRIBUTIONS OF MAIN WORKING HARMONICS

\begin{tabular}{|c|c|c|c|}
\hline Pole pairs & Contributions & $\begin{array}{c}\text { Conventional } \\
\text { multi-tooth FSPM }\end{array}$ & $\begin{array}{c}\text { Proposed } \\
\text { FSPM } \\
\end{array}$ \\
\hline \multirow{3}{*}{$\frac{7 N_{s}}{2}-N_{r}, 2$} & Back EMF (V) & 25.28 & 33.02 \\
\hline & Torque (Nm) & 10.11 & 13.21 \\
\hline & Proportion & $46.6 \%$ & $49.7 \%$ \\
\hline \multirow{3}{*}{$N_{r}-\frac{5 N_{s}}{2}, 4$} & Back EMF (V) & 16.61 & 20.73 \\
\hline & Torque (Nm) & 6.64 & 8.29 \\
\hline & Proportion (\%) & $30.6 \%$ & $31.2 \%$ \\
\hline \multirow{3}{*}{$\frac{9 N_{s}}{2}-N_{r}, 8$} & Back EMF (V) & 1.15 & 1.19 \\
\hline & Torque (Nm) & 0.46 & 0.47 \\
\hline & Proportion (\%) & $2.1 \%$ & $1.8 \%$ \\
\hline \multirow{3}{*}{$N_{r}-\frac{3 N_{s}}{2}, 10$} & Back EMF (V) & -2.21 & 0.18 \\
\hline & Torque (Nm) & -0.88 & 0.07 \\
\hline & Proportion (\%) & $-4.1 \%$ & $0.3 \%$ \\
\hline \multirow{3}{*}{$\frac{11 N_{s}}{2}-N_{r}, 14$} & Back EMF (V) & -0.06 & 0.35 \\
\hline & Torque (Nm) & -0.02 & 0.14 \\
\hline & Proportion (\%) & $-0.1 \%$ & $0.5 \%$ \\
\hline \multirow{3}{*}{$N_{r}-\frac{N_{s}}{2}, 16$} & Back EMF (V) & 7.71 & 6.31 \\
\hline & Torque (Nm) & 3.08 & 2.52 \\
\hline & Proportion (\%) & $14.2 \%$ & $9.5 \%$ \\
\hline \multirow{3}{*}{$\frac{13 N_{s}}{2}-N_{r}, 20$} & Back EMF (V) & 0.27 & 0.31 \\
\hline & Torque (Nm) & 0.11 & 0.12 \\
\hline & Proportion (\%) & $0.5 \%$ & $0.4 \%$ \\
\hline \multirow{4}{*}{$\frac{N_{s}}{2}+N_{r}, 22$} & Back EMF (V) & 5.47 & 4.36 \\
\hline & Torque (Nm) & 2.19 & 1.74 \\
\hline & Proportion (\%) & $10.2 \%$ & $6.6 \%$ \\
\hline & Back EMF (V) & 54.22 & 66.45 \\
\hline \multirow[t]{2}{*}{ Total } & Torque (Nm) & 21.69 & 26.56 \\
\hline & Proportion (\%) & $100 \%$ & $100 \%$ \\
\hline
\end{tabular}

TABLE III

OPTIMIZED DESIGN PARAMETERS

\begin{tabular}{|c|c|c|}
\hline Parameters & $\begin{array}{c}\text { Conventional } \\
\text { multi-tooth FSPM }\end{array}$ & $\begin{array}{c}\text { Proposed } \\
\text { FSPM }\end{array}$ \\
\hline Stator slot number & 6 & \\
\hline Rotor slot number & 19 & \\
\hline Stator outer diameter $(\mathrm{mm})$ & 126 & \\
\hline Rotor outer diameter (mm) & 74.4 & \\
\hline Rotor speed (rpm) & 400 & \\
\hline Magnet volume (mL) & 36.7 & 42.1 \\
\hline Spoke-type magnet thickness $t_{s}(\mathrm{~mm})$ & 3.6 & 3 \\
\hline Auxiliary slot depth $d_{a}(\mathrm{~mm})$ & 3 & 2 \\
\hline Inner auxiliary tooth width $w_{i}(\mathrm{~mm})$ & 4.5 & 4.8 \\
\hline Outer auxiliary tooth width $w_{o}(\mathrm{~mm})$ & 4.8 & 5.3 \\
\hline Phase current (A) & 7.9 & \\
\hline Magnet remanence $(\mathrm{T})$ & 1.26 & \\
\hline Stack length $(\mathrm{mm})$ & 70 & \\
\hline Airgap length (mm) & 0.5 & \\
\hline Series turns per phase & 100 & \\
\hline Rotor tooth width $w_{r}(\mathrm{~mm})$ & 4.8 & 4.4 \\
\hline
\end{tabular}

EMFs are $66.45 \mathrm{~V}$ and $64.57 \mathrm{~V}$ respectively for the proposed FSPM machine.

\section{Electromagnetic Performance}

In this section, the electromagnetic performance of the proposed FSPM machine, including the back EMF, cogging torque, electromagnetic torque and power factor will be compared with the conventional multi-tooth FSPM machine. To realize a fair comparison, stator outer/inner diameter, airgap length, stack length and current density are selected as the same. The optimized design parameters are listed in Table III.

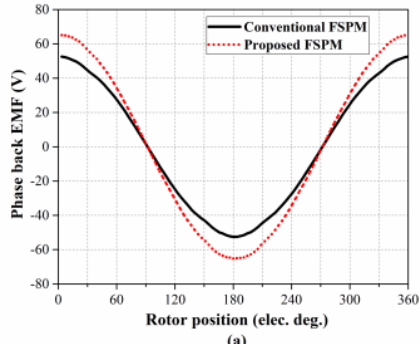

(a)

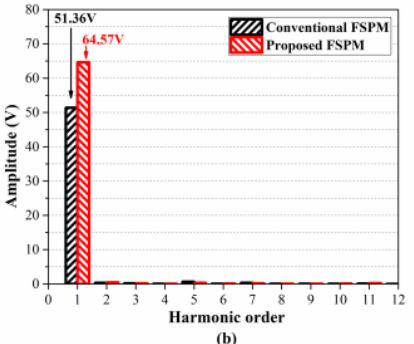

Fig. 10. FEA-predicted phase back EMFs. (a) Phase back EMFs versus rotor position. (b) FFT analysis.

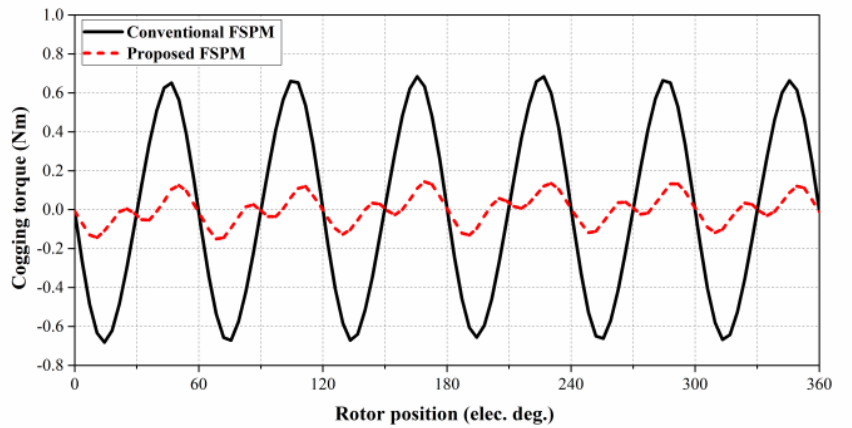

Fig. 11. FEA-predicted cogging torque waveforms of conventional multi-tooth and proposed FSPM machines.

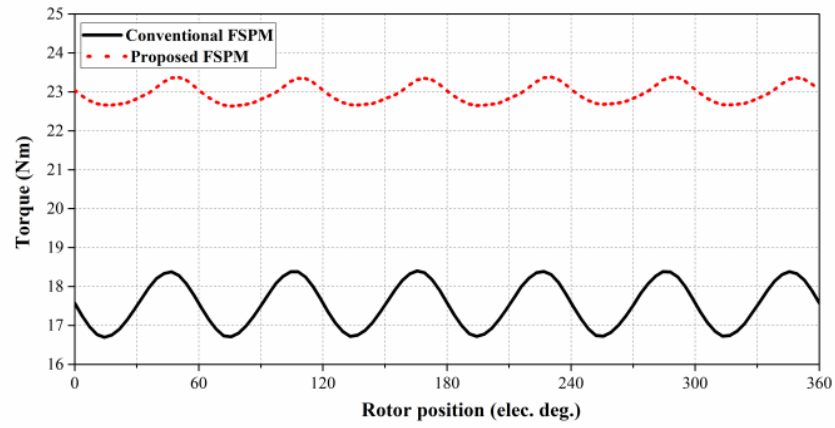

Fig. 12. FEA-predicted torque waveforms.

\section{A. Back EMF}

Fig. 10 shows the FEA-predicated phase back-EMF waveforms and FFT analysis results. The amplitude of the phase back-EMF fundamental harmonic increases by $25.7 \%$ compared with the conventional multi-tooth FSPM machine. The calculated THD values in conventional multi-tooth and proposed machines are $1.5 \%$ and $1.0 \%$ respectively. Therefore, the harmonic contents of the proposed FSPM machine are lower. The back EMF is less affected by rotor permeance higher harmonics. Hence, it is reasonable to neglect the rotor permeance harmonics in the previous analysis.

\section{B. Cogging Torque}

Fig. 11 shows the FEA-predicted cogging torque waveforms of the conventional multi-tooth and proposed FSPM machines. The amplitudes of the cogging torque are $0.68 \mathrm{Nm}$ and $0.14 \mathrm{Nm}$ respectively. The cogging torque of the new topology decreases by $79.4 \%$ compared with the conventional one.

\section{Electromagnetic Torque}

The current density at the rated load is selected as $5 \mathrm{~A} / \mathrm{mm}^{2}$, so the corresponding phase current is 7.9 A. Fig. 12 shows the FEA-predicted torque waveforms. The average torques of the 


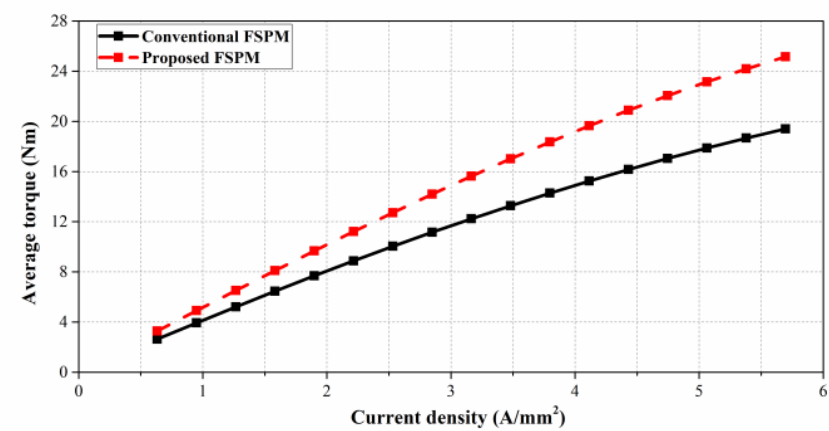

Fig. 13. FEA-predicted average torque-current density curves.

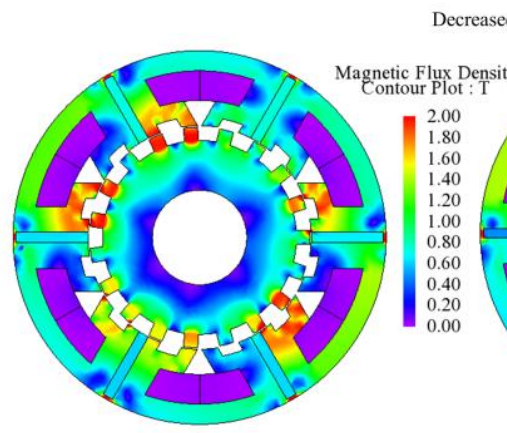

(a)

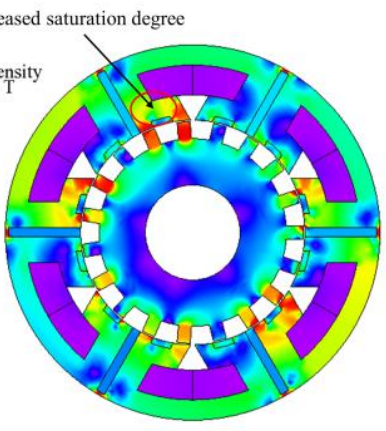

(b)
Fig. 14. On-load contour plots. (a) Conventional multi-tooth FSPM machine. (b) Proposed FSPM machine.

conventional multi-tooth and proposed FSPM machines are $17.55 \mathrm{Nm}$ and $22.96 \mathrm{Nm}$ respectively, thus the average torque increases by $30.8 \%$. Thus, the torque per magnet volume values are $477 \mathrm{Nm} / \mathrm{L}$ and $544 \mathrm{Nm} / \mathrm{L}$ respectively. The torque ripples are $9.7 \%$ and $3.2 \%$ respectively, therefore torque ripple decreases by $67.0 \%$. The lower torque ripple is mainly because of the lower cogging torque.

Fig. 13 shows the FEA-predicted average torque versus current density curves. It can be seen from the figure that the curve of the proposed FSPM machine has better linearity than the conventional multi-tooth FSPM machine. It is mainly because the saturation degree of the iron core decreases by adopting the novel topology, as shown in Fig. 14.

\section{Power Factor}

The power factor of the FSPM machines can be given as

$$
P F=1 / \sqrt{1+\left(\omega L_{\mathrm{s}} I_{A} / E_{A}\right)^{2}}
$$

where $L_{\mathrm{s}}$ is the synchronous inductance.

The phase synchronous inductances of the conventional multi-tooth and proposed FSPM machines are calculated as $11.9 \mathrm{mH}$ and $12.2 \mathrm{mH}$ respectively by adopting the frozen permeability method.

Fig. 15 shows the FEA-predicted power factor versus current density curves. The power factor of the proposed FSPM machines is higher than the conventional one and increases by $15.6 \%$ at the rated current. The reason is that the phase back EMF of the proposed FSPM machine is much greater than the conventional multi-tooth FSPM machine, while the inductances of the two topologies are very close.

\section{E. Demagnetization Examination}

In order to confirm the feasibility of PM thickness of the proposed FSPM machine with dual sets of magnet

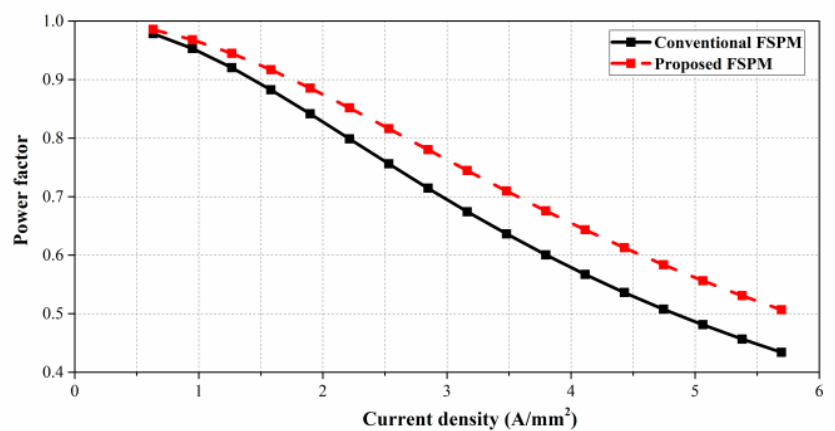

Fig. 15. FEA-predicted power factor versus current density curves.

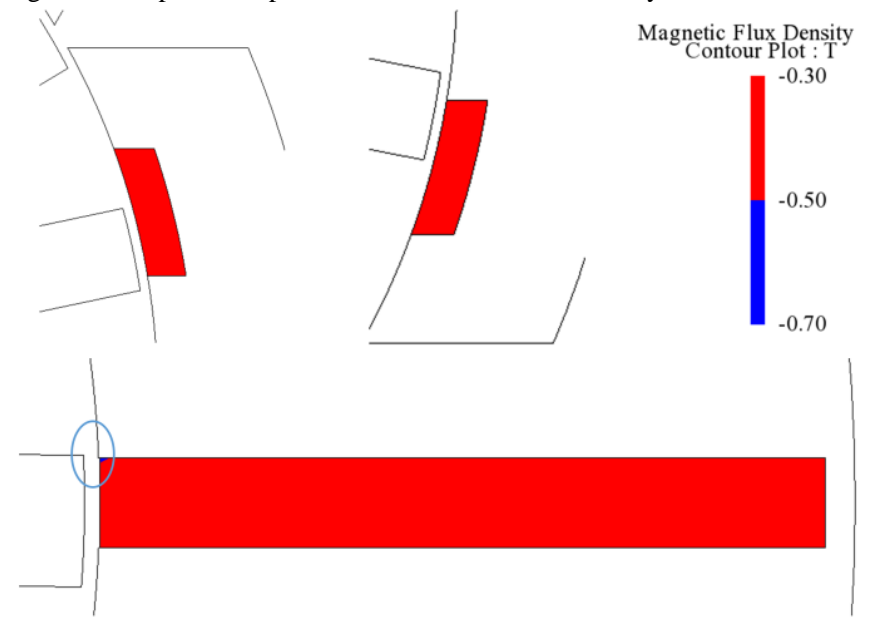

Fig. 16. Contour plots under 2 times overload operation.

TABLE IV

LOSS AND EFFICIENCY @ RATED LOAD

\begin{tabular}{lcc}
\hline \multicolumn{1}{c}{ Items } & $\begin{array}{c}\text { Conventional } \\
\text { multi-tooth FSPM }\end{array}$ & Proposed FSPM \\
\hline Copper loss (W) & \multicolumn{3}{c}{57.0} \\
Stator iron loss (W) & 21.8 & 25.1 \\
Rotor iron loss (W) & 28.2 & 26.8 \\
PM eddy-current loss (W) & 1.3 & 1.6 \\
Total loss (W) & 108.3 & 110.5 \\
Efficiency & 0.87 & 0.90 \\
\hline \hline
\end{tabular}

arrangements, demagnetization withstanding capability is examined. Fig. 16 shows the contour plots under 2 times overload operation, and the PM material and the working temperature are set as $\mathrm{N} 40 \mathrm{EH}$ and $120^{\circ} \mathrm{C}$ respectively. It is observed that only a very small part of the spoke-type magnet is demagnetized, since the reference knee flux density is $-0.5 \mathrm{~T}$.

\section{F. Loss and Efficiency}

The loss and efficiency of the conventional multi-tooth and proposed FSPM machines are listed in Table IV. It can be observed that the total losses of the conventional multi-tooth and proposed FSPM machines are comparable. But the proposed topology has higher efficiency due to the higher output torque.

\section{DESIGN OPTIMIZATION AND INFLUENCE OF GEOMETRIC PARAMETERS}

In this section, the proposed FSPM machine with dual sets of magnet arrangements will be optimized by adopting a multiobjective genetic algorithm. Based on the global optimization design, the influence of geometric parameters is investigated to reveal some design guidelines for the proposed FSPM topology. 


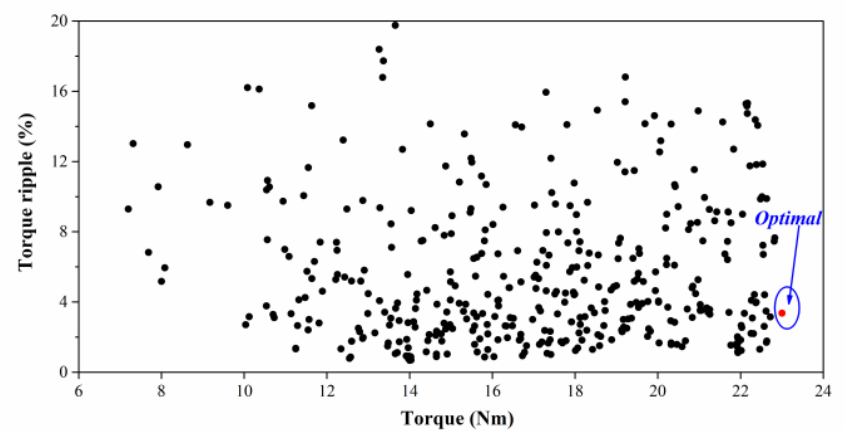

Fig. 17. Optimization results of proposed FSPM topology.

TABLE V

RANGE OF MAIN DESIGN PARAMETERS

\begin{tabular}{lc}
\hline \hline \multicolumn{1}{c}{ Parameters } & Range \\
\hline Stator inner diameter & $31.5 \sim 44.1 \mathrm{~mm}$ \\
Spoke-type magnet thickness $t_{s}$ & $2 \sim 5 \mathrm{~mm}$ \\
Surface-mounted magnet thickness $d_{a}$ & $1 \sim 3 \mathrm{~mm}$ \\
Inner auxiliary tooth width $w_{i}$ & $1 \sim 7.5 \mathrm{~mm}$ \\
Outer auxiliary tooth width $w_{o}$ & $1 \sim 7.5 \mathrm{~mm}$ \\
Rotor tooth width $w_{r}$ & $2 \sim 8 \mathrm{~mm}$ \\
\hline \hline
\end{tabular}

\section{A. Design Optimization}

As shown in Fig. 17, a multi-parameter optimization adopting the multi-objective genetic algorithm has been added to explain the parameter selection. It can be seen that the parameters are optimal. The current density at the rated load is $5 \mathrm{~A} / \mathrm{mm}^{2}$ and the slot fill factor is 0.48 . The main design parameters and the corresponding scopes are listed in Table V. The global optimization goal is to maximize the average torque and minimize the torque ripple.

It can be seen that the optimal case is selected when the average torque and torque ripple can be well balanced. The corresponding geometric parameters are selected to design the proposed FSPM machine.

\section{B. Influences of Magnet Thickness}

The magnet thickness, which is critical to the cost, has a significant influence on the performance of the proposed FSPM machines with dual sets of magnet arrangements.

Fig. 18(a) and Fig. 19(a) show the influence of spoke-type and surface-mounted magnet thickness on average torque. The influence of magnet thickness on average torque is analyzed separately with magnet of another type fixed. Surface-mounted magnet thickness mainly influences the saturation degree of stator core. It is found that average torque is very sensitive to the position of auxiliary tooth axis due to modulation effect. Therefore, the auxiliary tooth axis position remains unchanged to possibly only research the impact of magnet thickness.

With the increase of the spoke-type magnet thickness, average torque firstly increases mainly due to the increase of flux density and enhancement of modulation effect. The average torque reaches the maximum value when spoke-type magnet thickness is $3 \mathrm{~mm}$. Then the average torque decreases despite the increase of magnet thickness and this is mainly due to the saturated stator core and weakened modulation effect.

Fig. 18(b) and Fig. 19(b) present the cogging torque versus the magnet thickness curves. Compared with the surfacemounted magnet, the cogging torque is more sensitive to the change of the spoke-type magnet thickness. It is mainly because
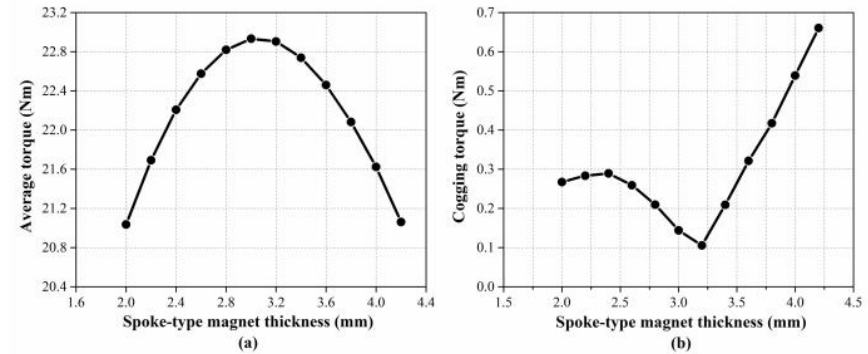

Fig. 18. Influence of spoke-type magnet thickness. (a) Average torque. (b) Cogging torque.
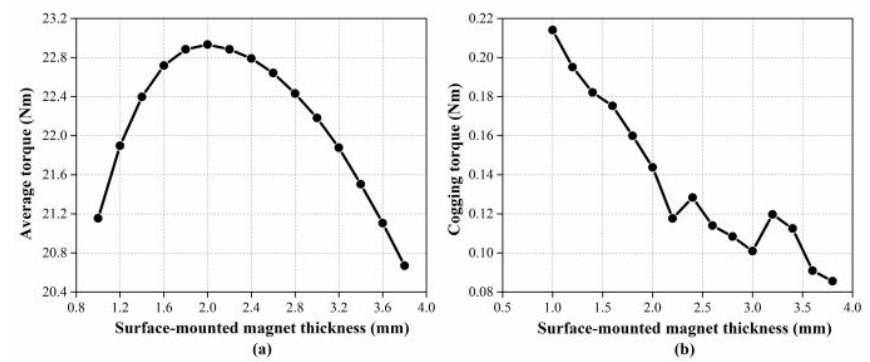

Fig. 19. Influence of surface-mounted magnet thickness. (a) Average torque. (b) Cogging torque.

the position of the inner auxiliary tooth changes with the increase of the spoke-type magnet thickness.

The cogging torque is very sensitive to the position of the auxiliary tooth axis due to the modulation effect. The influence of spoke-type magnet thickness on cogging torque is analyzed with surface-mounted magnet width changed to keep the axis of auxiliary tooth still. When the spoke-type magnet thickness reaches $3.6 \mathrm{~mm}$ and continue to increase, the width of inner auxiliary tooth decreases by twice the increase of magnet thickness. When the spoke-type magnet thickness is small, the cogging torque is low due to the small MMF.

To obtain the high torque density and low cogging torque, the thicknesses of the spoke-type and surface-mounted magnet are $3 \mathrm{~mm}$ and $2 \mathrm{~mm}$.

\section{Influences of Auxiliary/Rotor Tooth Width}

Fig. 20(a), Fig. 21(a) and Fig. 22(a) show the average torque versus the tooth width curves. Since auxiliary teeth and magnets are in contact, it is impossible to analyze the impact of the single parameter. To provide the main parameters which affects the electromagnetic performance most, the influence of inner/outer auxiliary tooth width is analyzed with surface-mounted magnet width changed and other parameters unchanged. The average torques all increase firstly, then reach the maximum values, and finally decrease.

Fig. 20(b), Fig. 21(b) and Fig. 22(b) present the cogging torque versus the tooth width curves. It is well known that the tooth width has a direct influence on the cogging torque. Compared with the curves in Fig. 18(b) and Fig. 19(b), the cogging torque is much more sensitive to the tooth width. The sensitivity of cogging torque mainly depends on the width and axis of auxiliary teeth. Different from Fig. 18, the width and axis of auxiliary teeth are both changed because the auxiliary teeth and magnets are in contact. Hence, cogging torque is more sensitive to the changes of inner and outer auxiliary tooth width. Thus, the high torque density and low cogging torque can be realized by choosing the appropriate tooth width. 

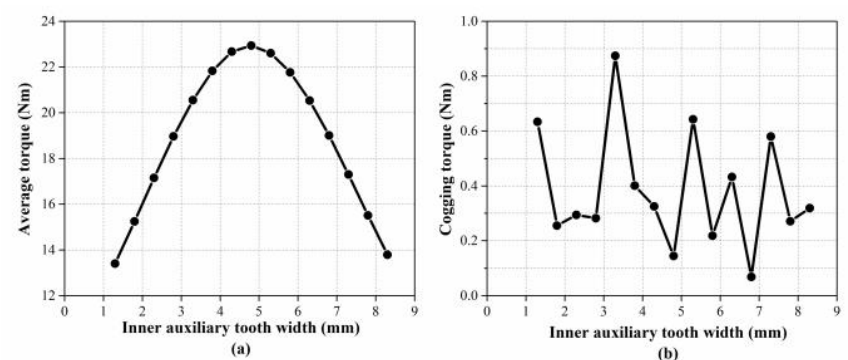

Fig. 20. Influence of inner auxiliary tooth width. (a) Average torque. (b) Cogging torque.
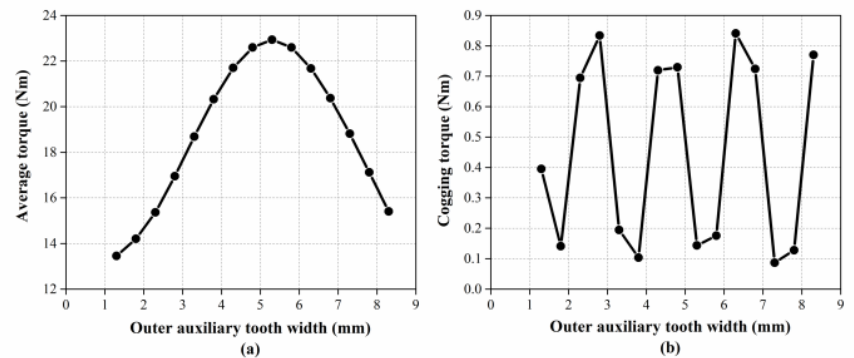

Fig. 21. Influence of outer auxiliary tooth width. (a) Average torque. (b) Cogging torque.

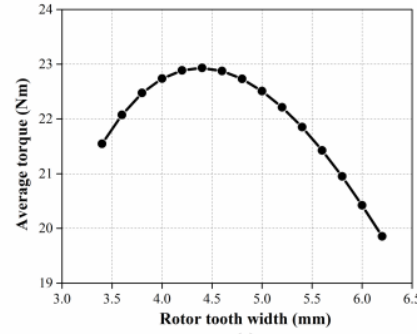

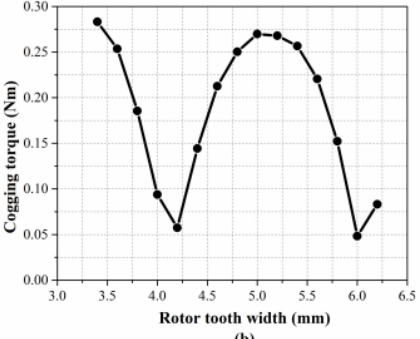

(b)
Fig. 22. Influence of rotor tooth width. (a) Average torque. (b) Cogging torque.

TABLE VI

VARIATION OF TORQUE PERFORMANCE OF MAIN COMBINATIONS

\begin{tabular}{ccccc}
\hline \hline \multirow{2}{*}{ Combination } & \multicolumn{2}{c}{ Average torque(Nm) } & \multicolumn{2}{c}{ Torque/Machine volume(Nm/L) } \\
\cline { 2 - 5 } & Conventional & Proposed & Conventional & Proposed \\
\hline $6 / 24 / 17$ & 16.72 & 21.54 & 19.16 & 24.69 \\
$6 / 24 / 19$ & 17.55 & 22.96 & 20.11 & 26.31 \\
$6 / 36 / 29$ & 14.56 & 22.73 & 16.68 & 26.05 \\
$6 / 36 / 31$ & 16.33 & 23.28 & 18.71 & 26.68 \\
$12 / 48 / 34$ & 17.00 & 21.76 & 19.48 & 24.94 \\
$12 / 48 / 35$ & 17.30 & 22.44 & 19.83 & 25.72 \\
$12 / 48 / 37$ & 18.02 & 22.88 & 20.65 & 26.22 \\
$12 / 48 / 38$ & 18.03 & 22.74 & 20.66 & 26.06 \\
$12 / 72 / 59$ & 11.98 & 17.11 & 13.73 & 19.61 \\
\hline \hline
\end{tabular}

* Note: 6/24/19 represents that 6 stator slots/24 auxiliary teeth/19 rotor teeth.

To achieve the best electromagnetic performance of the proposed FSPM machine with dual sets of magnet arrangements, the widths of inner auxiliary tooth, outer auxiliary tooth and rotor tooth are $4.8 \mathrm{~mm}, 5.3 \mathrm{~mm}$ and $4.4 \mathrm{~mm}$.

\section{Investigation of Different Stator/Rotor Combinations}

The variation of torque performance of main stator/rotor combinations is shown in Table VI.

The ratio of rotor pole-pair number and winding pole-pair number is defined as pole ratio of FSPM machines. In general, the higher the pole ratio, the higher the torque density. For instance, the torque capability of $6 / 24 / 19$ is greater than the counterpart of $6 / 24 / 17$. But it is noted that the torque density of

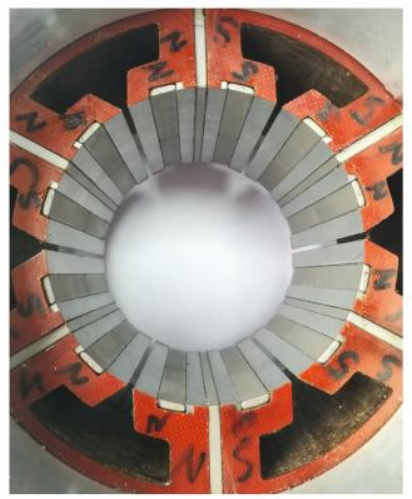

(a)

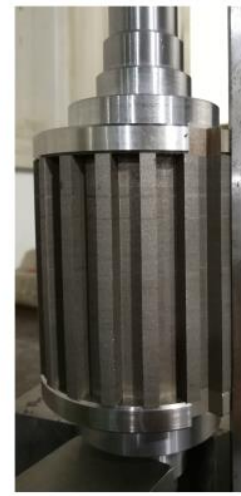

(b)
Fig. 23. Main parts of the prototype. (a) Stator. (b) Rotor.

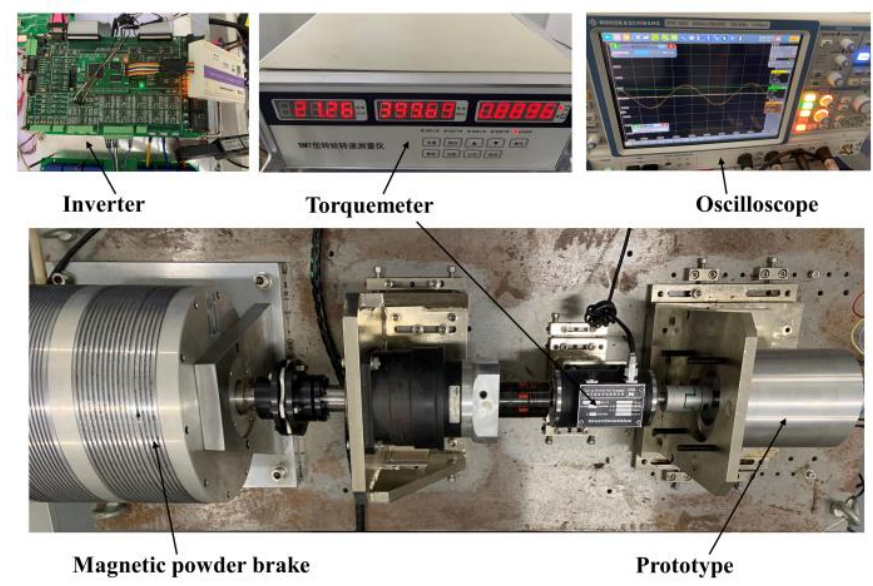

Fig. 24. On-load experimental test bench.

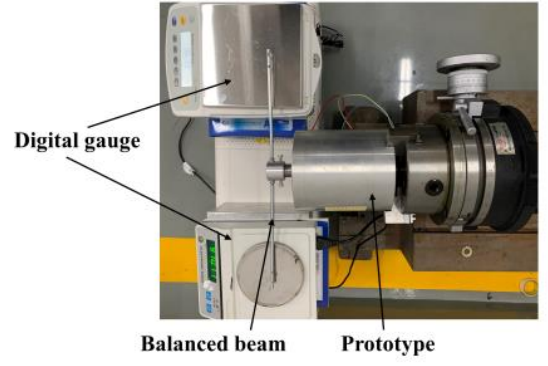

Fig. 25. Cogging torque test platform.

$6 / 36 / 31$ is lower than the counterpart of $6 / 24 / 19$. The reason is that the spoke-type magnet is thinner with the increase of the auxiliary tooth number to maintain the modulation capability of the stator teeth. More basically, PM excitation capability and modulation capability of the stator teeth should be balanced in some stator/rotor combinations. It can be seen that the average torque of 12/72/59 is much smaller than the counterpart of $6 / 24 / 19$. Thus, the stator/rotor combinations of large auxiliary tooth number is not suitable for the machines of small size.

\section{PROTOTYPE AND EXPERIMENTS}

In order to verify the foregoing analysis, a prototype of the proposed FSPM machine has been manufactured. The main parts of the prototype are shown in Fig. 23. The on-load experimental test bench for prototype is illustrated in Fig. 24. Fig. 25 shows the cogging torque test platform for the prototype.

Fig. 26 shows the FEA-predicted and tested line back-EMF waveforms. The errors between the FEA-predicted and 


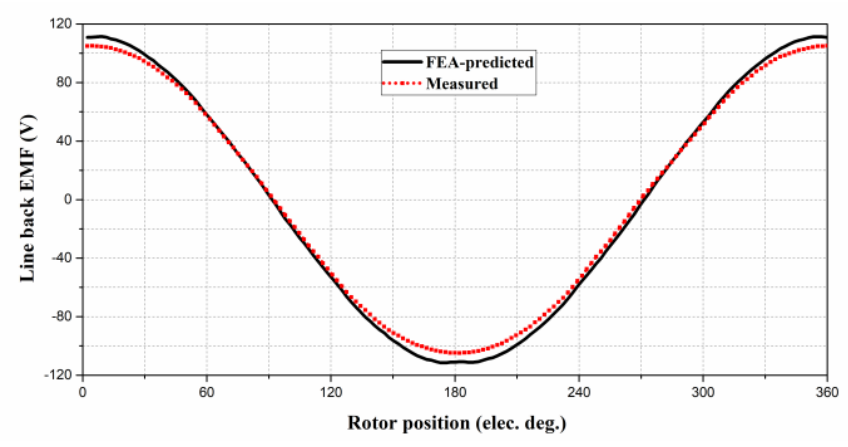

Fig. 26. FEA-predicted and tested line back-EMF waveforms.

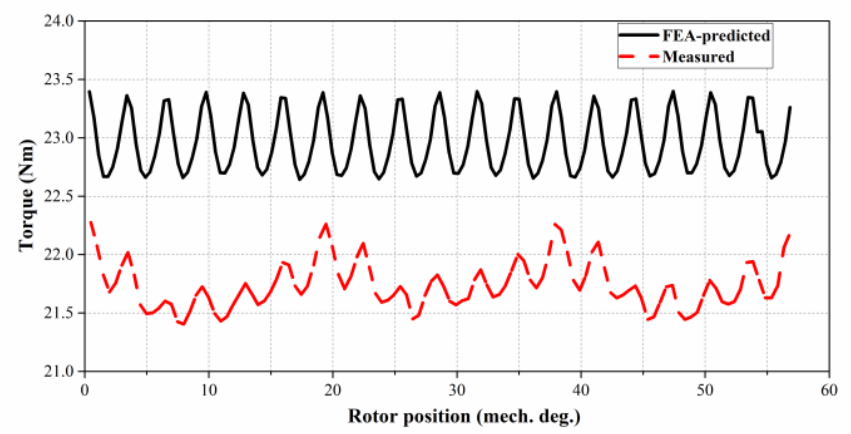

Fig. 27. FEA-predicted and measured torque waveforms under $5 \mathrm{~A} / \mathrm{mm}^{2}$.

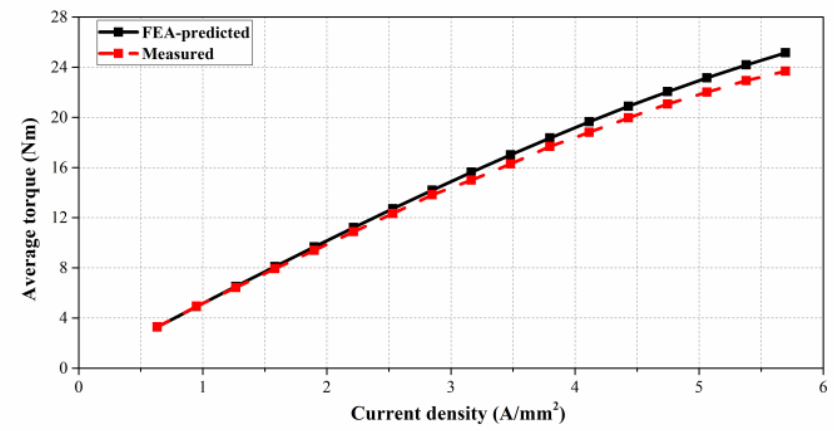

Fig. 28. Average torque versus current density curves measured by experiments and predicted by FEA.

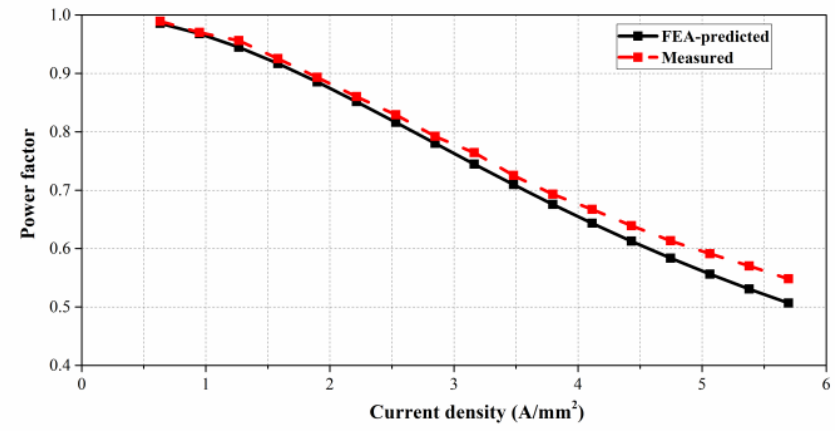

Fig. 29. Power factor versus current density curves measured by experiments and predicted by FEA.

measured back EMF are mainly due to the end-effects and manufacturing tolerances. The FEA-predicted and measured torque waveforms are shown in Fig. 27. The period of the torque ripple is influenced by the cogging torque, as shown in Fig. 31. Fig. 28 presents the average torque versus the current density curves predicted by FEA and measured by experiments. It is shown that the errors increase with the increase of current which causes the temperature rise. It is noted that the measurements are slightly lower than the FEA-predictions, which is mainly because the manufacture tolerance and end

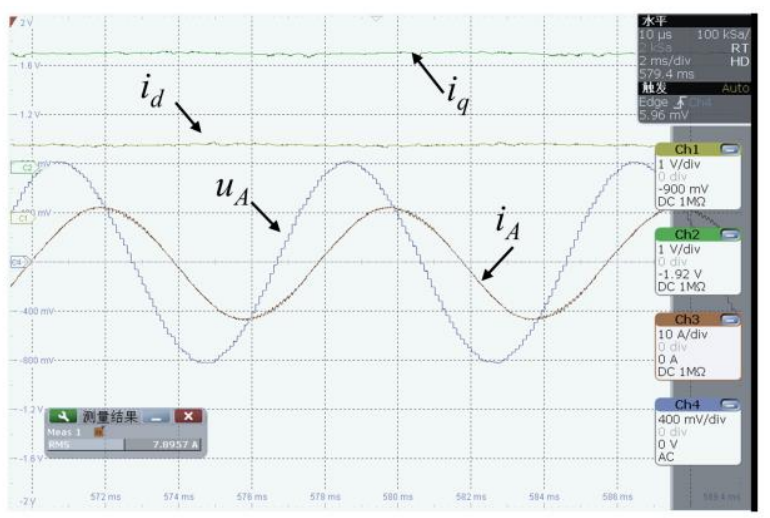

Fig. 30. Experimental waveforms.

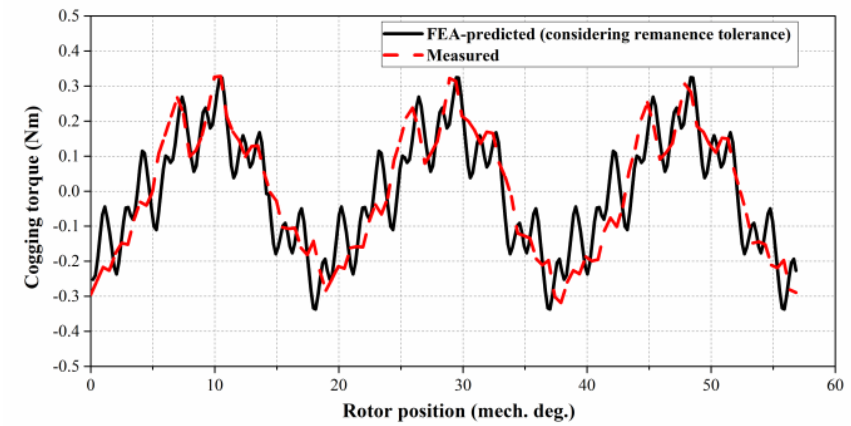

Fig. 31. Cogging torque waveforms predicted by FEA considering remanence tolerance and measured by experiments.

effect are not considered in the simulation.

Fig. 29 shows the power factor versus current density curves measured by experiments and predicted by FEA. Furthermore, the experimental waveforms are presented in Fig. 30, including $i_{d}$ and $i_{q}$. The measured cogging torque waveform is shown in Fig. 31. It is noted that the period of the tested cogging torque is very close to 18.95 mechanical degree which is the period of rotor permeance. The additional cogging torque components are caused by stator tolerances. The manufacturing tolerances can be tolerance of PMs and tolerance of stator core. To verify the possible manufacturing tolerance, $4 \%$ is used for the remanence tolerance [25], i.e. the remanence of magnets under one stator main tooth are higher than other magnets. The cogging torque waveforms predicted by FEA and measured by experiments match well. Thus, the period of the cogging torque of prototype may change due to the manufacturing tolerance. Nevertheless, the amplitude of the tested cogging torque is only $0.32 \mathrm{Nm}$.

\section{CONCLUSION}

In this paper, a novel FSPM machine with dual sets of magnet arrangements is proposed. Compared with the conventional multi-tooth FSPM machine, torque density of the proposed machine is significantly improved due to much increased working harmonic contents of MMF and significantly reduced non-working harmonics to maintain comparable saturation degrees. Furthermore, the cogging torque is also inherently reduced. The operating principle of the proposed topology is revealed based on MMF-permeance model and numerical FEA. The effect of geometric parameters such as magnet thickness, auxiliary tooth width and rotor tooth width on the average torque and cogging torque is also investigated. 
A prototype has been manufactured to validate the analysis conclusion. With only $14.7 \%$ increase of magnet usage, it is demonstrated that proposed topology can achieve $30.8 \%$ higher torque density, $79.4 \%$ lower cogging torque and $15.6 \%$ higher power factor than the conventional counterpart.

\section{REFERENCES}

[1] S. E. Rauth and L. J. Johnson, "Design principles of flux-switching alternators," AIEE Trans., vol. 74, pt. III, no. 3, pp. 1261-1268, Jan. 1955.

[2] T. Raminosoa, C. Gerada and M. Galea, "Design considerations for a fault-tolerant flux-switching permanent-magnet machine," IEEE Trans. Ind. Electron., vol. 58, no. 7, pp. 2818-2825, Jul. 2011.

[3] G. Zhang, W. Hua, M. Cheng and J. Liao, "Design and comparison of two six-phase hybrid-excited flux-switching machines for EV/HEV applications," IEEE Trans. Ind. Electron., vol. 63, no. 1, pp. 481-493, Jan. 2016.

[4] Z. Q. Zhu, and J. T. Chen, "Advanced flux-switching permanent magnet brushless machines," IEEE Trans. Magn., vol. 46, no. 6, pp. 1447-1453, June. 2010.

[5] W. Hua, M. Cheng, and G. Zhang, "A novel hybrid excitation fluxswitching motor for hybrid vehicles," IEEE Trans. Magn., vol. 45, no. 10, pp. 4728-4731, Oct. 2009.

[6] R. L. Owen, Z. Q. Zhu, A. S. Thomas, G. W. Jewell and D. Howe, "Alternate poles wound flux-switching permanent-magnet brushless AC machines," IEEE Trans. Ind. Appl., vol. 46, no. 2, pp. 790-797, Mar./Apr. 2010.

[7] G. Zhang, W. Hua, and P. Han, "Quantitative evaluation of the topologies and electromagnetic performances of dual-three-phase flux-switching machines," IEEE Trans. Ind. Electron., vol. 65, no. 11, pp. 9157-9167, Nov. 2018

[8] J. T. Chen, and Z. Q. Zhu, "Comparison of all- and alternate-poles-wound flux-switching PM machines having different stator and rotor pole numbers," IEEE Trans. Ind. Appl., vol. 46, no. 4, pp. 1406-1415, Jul./Aug. 2010.

[9] W. Fei, P. C. K. Luk, J. X. Shen, Y. Wang and M. Jin, "A novel permanent-magnet flux switching machine with an outer-rotor configuration for in-wheel light traction applications," IEEE Trans. Ind. Appl., vol. 48, no. 5, pp. 1496-1506, Sep./Oct. 2012.

[10] M. Lin, L. Hao, X. Li, X. Zhao and Z. Q. Zhu, "A novel axial field fluxswitching permanent magnet wind power generator," IEEE Trans. Magn., vol. 47, no. 10, pp. 4457-4460, Oct. 2011.

[11] Z. Q. Zhu, A. S. Thomas, J. T. Chen and G. W. Jewell, "Cogging torque in flux-switching permanent magnet machines," IEEE Trans. Magn., vol. 45, no. 10, pp. 4708-4711, Oct. 2009.

[12] X. Zhu, W. Hua, Z. Wu, W. Huang, H. Zhang, and M. Cheng, "Analytical approach for cogging torque reduction in flux-switching permanent magnet machines based on magnetomotive force-permeance model," IEEE Trans. Ind. Electron., vol. 65, no. 3, pp. 1965-1979, Mar. 2018.

[13] J. T. Chen, Z. Q. Zhu, S. Iwasaki and R. P. Deodhar, "A novel E-core switched-flux PM brushless AC machine," IEEE Trans. Ind. Appl., vol. 47, no. 3, pp. 1273-1282, May/Jun. 2011.

[14] J. Chen, Z. Zhu, S. Iwasaki, and R. Deodhar, "Influence of slot opening on optimal stator and rotor pole combination and electromagnetic performance of switched-flux PM brushless AC machines," IEEE Trans. Ind. Appl., vol. 47, no. 4, pp. 1681-1691, Jul./Aug. 2011.

[15] L. Shao, W. Hua, Z. Q. Zhu, X. Zhu, M. Cheng, and Z. Wu, "A novel flux-switching permanent magnet machine with overlapping windings," IEEE Trans. Energy Convers., vol. 32, no. 1, pp. 172-183, Mar. 2017.

[16] W. Hua, H. Zhang, M. Cheng, J. Meng, and C. Hou, "An outer-rotor fluxswitching permanent-magnet-machine with wedge-shaped magnets for in-wheel light traction," IEEE Trans. Ind. Electron., vol. 64, no. 1, pp. 69-80, Jan. 2017.

[17] Y. Gao, D. Li, R. Qu, H. Fang, H. Ding and L. Jing, "Analysis of a novel consequent-pole flux switching permanent magnet machine with flux bridges in stator core," IEEE Trans. Energy Convers., vol. 33, no. 4, pp. 2153-2162, Dec. 2018.

[18] Y. J. Zhou and Z. Q. Zhu, "Torque density and magnet usage efficiency enhancement of sandwiched switched flux permanent magnet machines using V-shaped magnets," IEEE Trans. Magn., vol. 49, no. 7, pp. 38343837, Jul. 2013.

[19] Z. Q. Zhu, J. T. Chen, Y. Pang, D. Howe, S. Iwasaki, and R. Deodhar, "Analysis of a novel multi-tooth flux-switching PM brushless AC machine for high torque direct-drive applications," IEEE Trans. Magn., vol. 44, no. 11, pp. 4313-4316, Nov. 2008.

[20] J. T. Chen, Z. Q. Zhu, and D. Howe, "Stator and rotor pole combinations for multi-tooth flux-switching permanent-magnet brushless AC machines," IEEE Trans. Magn., vol. 44, no. 12, pp. 4659-4667, Dec. 2008.

[21] T. Zou, D. Li, R. Qu, D. Jiang and J. Li, "Advanced high torque density PM vernier machine with multiple working harmonics," IEEE Trans. Ind. Appl., vol. 53, no. 6, pp. 5295-5304, Nov.-Dec. 2017.

[22] D. Li, R. Qu, J. Li, W. Xu, and L. Wu, "Synthesis of flux switching permanent magnet machines," IEEE Trans. Energy Convers., vol. 31, no. 1, pp. 106-117, Mar. 2016.

[23] D. Li, R. Qu, J. Li, L. Xiao, L. Wu and W. Xu, "Analysis of torque capability and quality in vernier permanent-magnet machines," IEEE Trans. Ind. Appl., vol. 52, no. 1, pp. 125-135, Jan./Feb. 2016.

[24] W. Chu and Z. Q. Zhu, "Average torque separation in permanent magnet synchronous machines using frozen permeability," IEEE Trans. Magn., vol. 49, no. 3, pp. 1202-1210, Mar. 2013.

[25] J. Ou, Y. Liu, R. Qu, and M. Doppelbauer, "Experimental and theoretical research on cogging torque of $\mathrm{PM}$ synchronous motors considering manufacturing tolerances," IEEE Trans. Ind. Electron., vol. 65, no. 5, pp. 3772-3783, May. 2018.

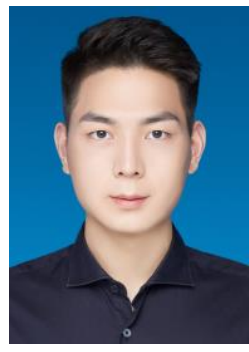

Canruo Chen was born in Hubei, China. $\mathrm{He}$ received the B.E.E. degree in electrical engineering from Wuhan University of Technology, Wuhan, China in 2015. He is currently studying for the Ph.D. degree in electrical engineering in Huazhong University of Science and Technology. He mainly researches the design and analysis of flux-modulation permanent magnet

brushless machines.

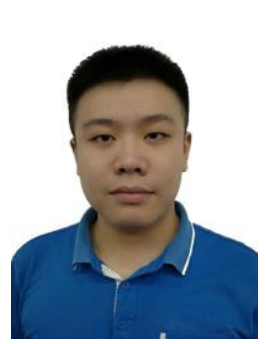

Xiang Ren was born in Hunan, China. He received the B.Eng. and Ph.D. degrees in electrical engineering from the Huazhong University of Science and Technology, Wuhan, China, in 2014 and 2019, respectively. He is currently a Postdoc with the Huazhong University of Science and Technology. His research interests include design and analysis of flux modulation

machines.

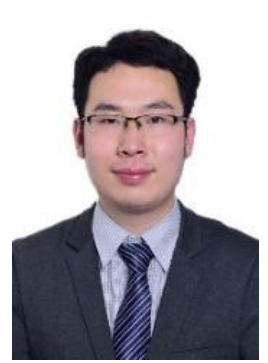

Dawei Li (S'12-M'15) was born in China. He received the B.E.E. degrees in electrical engineering from Harbin Institute of Technology, Harbin, China, in 2010 and the $\mathrm{Ph} . \mathrm{D}$. degree in electrical engineering from Huazhong University of Science \& Technology, in 2015. In Jul. 2015, he joined Huazhong University of Science \&Technology, Wuhan, China. Dr. Li has authored over 60 published technical papers and is the holder of over 10 patents/patent applications. He was recipient of the Best Poster Presentation Award from the XXII th International Conference on Electrical Machines (ICEM 2016), and Hubei Province Excellent Doctoral Dissertation (2016), China. His research areas include the design and analysis of fluxmodulation permanent-magnet brushless machines. 


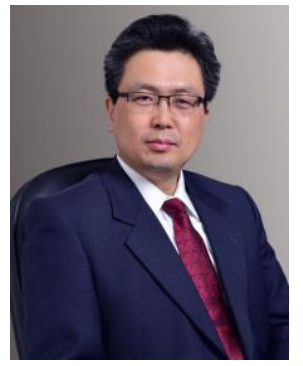

Ronghai Qu (S'01-M'02-SM'05-F'18) was born in China. He received the B.E.E. and M.S.E.E. degrees from Tsinghua University, Beijing, China, and the Ph.D. degree from the University of Wisconsin-Madison, Madison, WI, USA, in 1993, 1996, and 2002, respectively, all in electrical engineering. In 1998, he joined the Wisconsin Electric Machines and Power Electronics Consortiums, University of Wisconsin-Madison, WI, USA, as a Research Assistant. He became a Senior Electrical Engineer at Northland, a Scott Fetzer Company, Watertown, NY, USA, in 2002. Since 2003, he has been with the General Electric (GE) Global Research Center, Niskayuna, NY, USA, as a Senior Electrical Engineer in the Electrical Machines and Drives Laboratory. He has authored more than 230 published technical papers and is the holder of more than 50 patents/patent applications. Since 2010, he has been a Professor with Huazhong University of Science and Technology, Wuhan, China.

Dr. Qu is a full member of Sigma Xi. He has received several awards from the GE Global Research Center since 2003, including the Technical Achievement and Management Awards. He also received the 2003 and 2005 Best Paper Awards, third prize, from the Electric Machines Committee of the IEEE Industry Applications Society (IAS) at the 2002 and 2004 IAS Annual Meeting, respectively.

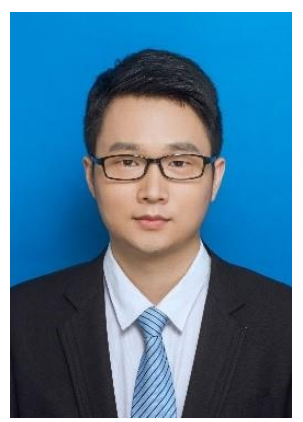

Kang Liu was born in Hubei, China. He received the B.E.E. degree in electrical engineering from Huazhong University of Science and Technology, Wuhan, China in 2018. He is currently studying for the M.S.E.E degree in electrical engineering in Huazhong University of Science and Technology. He mainly researches the suppression method of power electronic vibration, noise brought by the motor driver, and common mode current in the driving system.

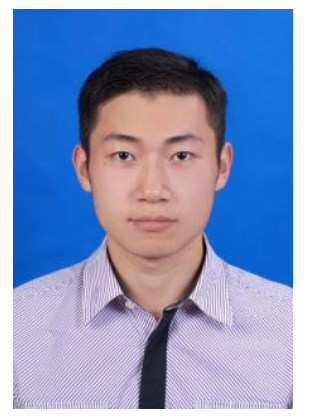

Tianjie Zou (S'15-M'18) was born in Hubei, China, in 1991. He received the B.Sc. degree in 2013 in electrical and electronic engineering, and Ph.D. degree in electrical engineering in 2018, both from Huazhong University of Science and Technology, Wuhan, China.

He joined the University of Nottingham, U.K., in 2018, as a research fellow within the Power Electronics, Machines and Control (PEMC) Group. In 2020, he was awarded Nottingham Research Fellowship and started his independent research career. His main research interests include design, analysis, and intelligent control of permanentmagnet machines. Dr. Zou was the recipient of the Best Paper
Award in the 22nd International Conference on Electrical Machines (ICEM 2016). 